\title{
Primary ovarian failure caused by a solvent containing 2-bromopropane
}

Jung-Min Koh, Chul-Hee Kim, Sung Kwan Hong, Ki-Up Lee, Young Tak Kim ${ }^{1}$, On Ja Kim ${ }^{2}$ and Ghi Su Kim

Division of Endocrinology and Metabolism, Department of Internal Medicine, ${ }^{1}$ Department of Obstetrics and Gynecology and

${ }^{2}$ Department of Diagnostic Pathology, Asan Medical Center, University of Ulsan College of Medicine, Seoul, South Korea

(Correspondence should be addressed to G S Kim, Department of Internal Medicine, Asan Medical Center, Song-Pa PO Box 145,

Seoul 138-040, South Korea)

\begin{abstract}
Sixteen Korean female laborers who had been exposed to a cleaning solvent composed mainly of 2-bromopropane developed primary ovarian failure. Histologic findings from these patients' ovaries were similar to those observed in ovarian failure caused by radiation or chemotherapy, i.e., reduced number and developmental arrest of primary follicles, interstitial fibrosis and hyalinization of blood vessels. We followed their clinical course for 2 years and found that two patients recovered normal ovarian function spontaneously: one became pregnant and delivered a normal full-term baby, and the other resumed regular menstrual periods with normal hormonal values. Our observations support the idea that the increasing prevalence of ovarian failure in recent years might be due to an increase in presently unidentified environmental toxic agents.
\end{abstract}

European Journal of Endocrinology 138 554-556

\section{Introduction}

Gonadal cells are one of the most actively proliferating cell types, and are susceptible to environmental toxic agents. Primary ovarian failure has reportedly increased in recent years and environmental factors have frequently been implicated as responsible for this increase (1). However, the reproductive toxicities of industrial materials have rarely been documented, except for lead (2) and some insecticides (3).

Kim et al. (4) reported recently that a group of female laborers who had been exposed to a solvent containing 2-bromopropane developed primary ovarian failure. We now report the pathologic findings from the ovaries and the results of clinical follow-up for 24 months.

\section{Subjects and methods}

Twenty-six women exposed to a cleaning solvent (Solvent \#5200), composed mainly of 2-bromopropane, complained of amenorrhea and irregular menstrual periods. Among these patients, 16 were diagnosed as having primary ovarian failure, and were included in this study. Diagnosis of primary ovarian failure was made by elevated serum luteinizing hormone (LH) and follicle-stimulating hormone (FSH) $(>30 \mathrm{mIU} / \mathrm{ml})$ with low estradiol $(<30 \mathrm{pg} / \mathrm{ml})$. The clinical characteristics of these patients are summarized in Table 1 . The median age of the subjects was 24 years (range 20-44 years), and their median duration of exposure was 11 months (range 4-16 months). All subjects insisted that they had regular menstrual periods previously, and declared no history of smoking, habitual alcohol drinking or prolonged use of oral contraceptive pills.

Among the patients who had ovarian failure, six gave informed consent and underwent laparoscopic examination. Ovarian biopsy was performed in four of them.

The patients received cyclic estrogen-progesterone replacement therapy and were followed-up for 24 months. In order to know whether the ovarian dysfunction was reversible, we discontinued the hormone replacement for 2-3 months at 6-month intervals and observed whether spontaneous menstruation resumed.

Results are presented as the median (range). Statistical analysis was performed using Mann-Whitney U-test to compare the clinical characteristics of the subjects with and without primary ovarian failure.

\section{Results}

The gross findings from the ovaries varied among the six subjects who underwent laparoscopy: atrophy, small size or near-normal appearance. However, microscopic findings were rather uniform in the cases who underwent ovarian biopsy (Fig. 1). Focal or diffuse fibrosis was noted in the ovarian cortex. Follicles did not show the various stages of development, indicating 


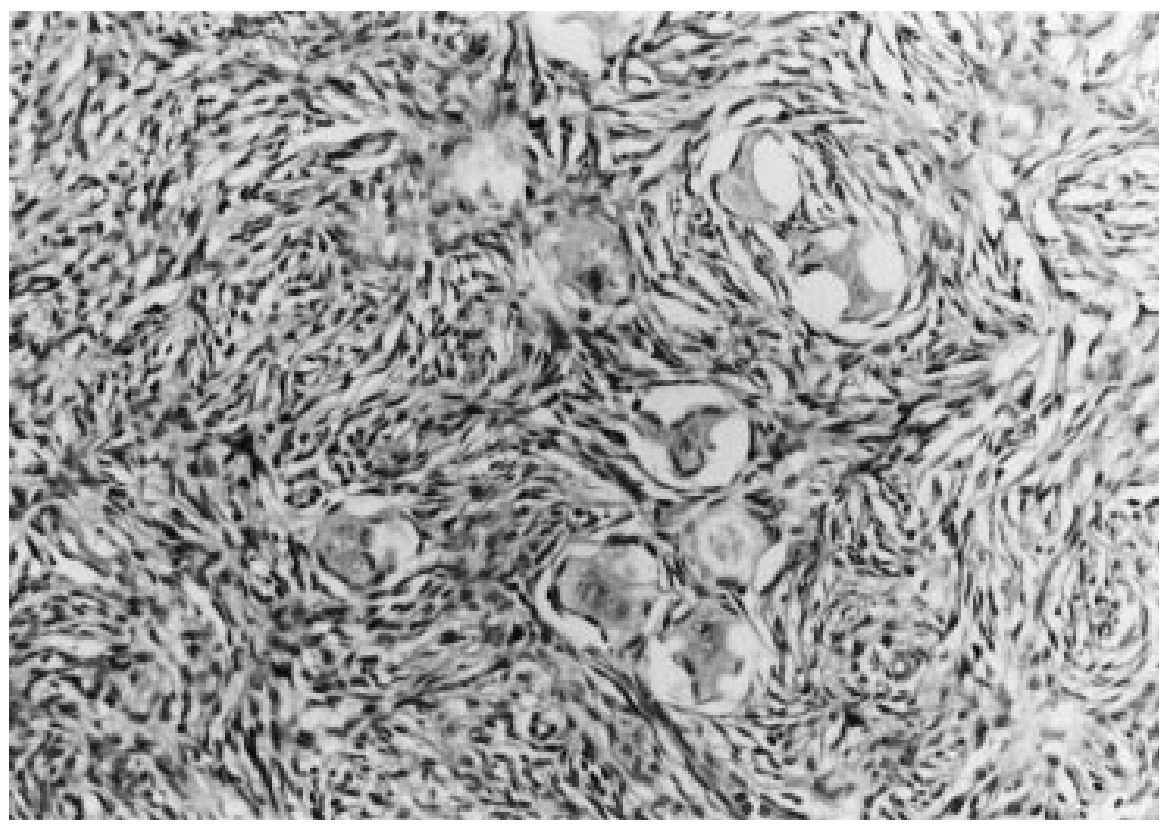

Figure 1 Light microscopic findings from the ovary, showing rare primary follicles in atrophic cortex. No developing stages of follicles are present (the findings were similar in three other cases). H \& E staining, $\times 200$.

developmental arrest. Primary follicles showed irregular atrophy, and the number of primary follicles was markedly decreased except in one case. Oocytes and granulosa cells were not seen in the primary follicles. The number of corpus albicans was decreased across the whole tissue. Hyalinization of blood vessels in the medulla was also noted.

During the follow-up of 24 months, amenorrhea persisted in most cases. However, two cases showed spontaneous recovery in ovarian function. One case was a 26-year-old woman, who had been exposed to the cleaning solvent for 16 months. Results of the initial hormonal study were serum LH $16.9 \mathrm{mIU} / \mathrm{ml}$, FSH $60.0 \mathrm{mIU} / \mathrm{ml}$ and estradiol below $10.0 \mathrm{pg} / \mathrm{ml}$. She was followed-up without hormone replacement therapy and her amenorrhea persisted. However, her urine human chorionic gonadotropin test was found to be positive after 7 months, and pelvic ultrasonography revealed that she was pregnant. Gestational age estimated by the size of fetal sac was 6 weeks at that time. Although the serum estradiol level was in the lower normal range for her gestational age $(102.0 \mathrm{pg} /$ $\mathrm{ml}$ ), low serum LH (below $2.0 \mathrm{mIU} / \mathrm{ml}$ ) and $\mathrm{FSH}$ $(2.0 \mathrm{mIU} / \mathrm{ml})$ levels suggested that her ovarian function had recovered. She delivered a normal full-term baby and breast-fed him. She was followed-up for 6 months after delivery. Her baby was healthy and her lactation was sufficient.

The other case was a 24-year-old woman who had been exposed to the cleaning solvent for 5 months. Results of the initial hormonal study were LH $49.0 \mathrm{mIU} /$ $\mathrm{ml}$, FSH $108.0 \mathrm{mIU} / \mathrm{ml}$, and estradiol $11.5 \mathrm{pg} / \mathrm{ml}$.
Twelve months after cyclic estrogen-progesterone therapy, she was found to have regained spontaneous menstruation. Since then, she has continued to have regular menstrual periods. The final hormonal values were $\mathrm{LH} 16.6 \mathrm{mIU} / \mathrm{ml}$, FSH $14.1 \mathrm{mIU} / \mathrm{ml}$, and estradiol $205.0 \mathrm{pg} / \mathrm{ml}$ on day 12 of her cycle.

\section{Discussion}

The extent and frequency of primary ovarian failure due to irradiation or anti-cancer chemotherapeutic agents are known to be related to the dose and duration of exposure, and the age of the subjects (5). Our findings are consistent with this (Table 1); the subjects who developed ovarian failure were characterized by a longer duration of exposure and older age.

The mechanism by which 2-bromopropane induces ovarian failure is presently unknown. 1,2-Dibromochloropropane (DBCP), a chemical structurally related to 2-bromopropane, reportedly causes male infertility in humans by direct DNA damage (6-8). As the chemical structure and in vivo metabolism of DBCP are very similar to those of 2-bromopropane, it can be suspected that bromopropane-induced ovarian failure also arises by direct DNA damage. However, except for ovary, testis and hematopoietic cells, the multiple organ damage caused by DBCP in human and animals (6) was not induced by 2-bromopropane. Therefore, further studies are needed to clarify the mechanism of 2-bromopropane-induced ovarian failure.

It is of interest that 2 out of 16 patients spontaneously recovered from established primary ovarian failure. 
Table 1 Clinical characteristics of female workers exposed to Solvent \#5200. Values are median (range).

\begin{tabular}{lll}
\hline & $\begin{array}{c}\text { Subjects with primary } \\
\text { ovarian failure } \\
(n=16)\end{array}$ & $\begin{array}{c}\text { Subjects without primary } \\
\text { ovarian failure } \\
(n=10)\end{array}$ \\
\hline Age (years) & $24(20-44)^{*}$ & $20(18-21)$ \\
Body weight $(\mathrm{kg})$ & $55(45-64)$ & $60(48-68)$ \\
Height $(\mathrm{cm})$ & $156(139-172)$ & $161(142-174)$ \\
Body mass index $\left(\mathrm{kg} / \mathrm{m}^{2}\right)$ & $22.7(20.1-26.2)$ & $22.9(20.2-25.2)$ \\
Age at menarche (years) & $15(11-17)$ & $14(12-17)$ \\
Duration of exposure (months) & $11(4-16)^{*}$ & $6.5(2-14)$ \\
Cases with gestational history & $5 / 16(31.3 \%)$ & $3 / 10(30.0 \%)$ \\
Serum LH level (mIU/ml) & $32.9(10.1-93.0)^{*}$ & $8.5(1.1-13.9)$ \\
Serum FSH level $(\mathrm{mlU} / \mathrm{ml})$ & $87.7(31.8-119.7)^{*}$ & $9.8(3.3-28.3)$ \\
Serum estradiol level $(\mathrm{pg} / \mathrm{ml})$ & $11.0(7.0-28.0)^{*}$ & $48.0(12.0-205.0)$ \\
\hline
\end{tabular}

${ }^{*} P<0.05$ vs the subjects without ovarian failure.

Recovery from ovarian failure may take a long time, and Spinelli $e t$ al. reported cases that recovered 7 years after exposure to radiation or anti-cancer chemotherapy (9). Jones et al. explained this phenomenon as follows: oocytes in an insensitive state of development may remain undamaged during exposure to toxins, and these oocytes might resume the cycle after a long period of amenorrhea (10). If this is the case, it can be expected that recovery rate might be even higher if we followed-up these patients for a longer period.

One limitation of our study is that neither the FSH/LH nor estradiol concentrations are accurate and highly specific markers of future ovarian function. As an additional marker for future ovarian activity, measurements of inhibin concentrations might have been useful. Inhibin is a recently discovered ovarian endocrine factor, and can regulate pituitary FSH release. In addition, recent findings also suggest that inhibin may be a local mediator of gonadotropin stimulation of folliculogenesis $(11,12)$.

In summary, a solvent containing 2-bromopropane caused primary ovarian failure in humans. The pathologic findings from these ovaries were similar to those observed in the ovarian failure caused by other environmental toxic agents. Some of the patients recovered spontaneously during the follow-up. Our observation supports the idea that the increasing prevalence of ovarian failure in recent years might be due to an increase in presently unidentified environmental toxic agents (1).

\section{References}

1 Mattison DR, Plowchalk DR, Meadows MJ, Al-Juburi AZ, Gandy J \& Malek A. Reproductive toxicity: male and female reproductive systems as targets for chemical injury. Medical Clinics of North America 199074 391-411.

2 Lancranjan I, Popescue HI, Gavanescu O, Klepsch I \& Serbanescu M. Reproductive ability of workmen occupationally exposed to lead. Archives of Environmental Health 197530 396-401.

3 Kupfer D. Effects of pesticides and related compounds on steroid metabolism and function. Critical Reviews in Toxicology 19754 83124.

4 Kim Y, Jung K, Hwang T, Jung G, Kim H, Park J et al. Hematopoietic and reproductive hazards of Korean electronic workers exposed to solvents containing 2-bromopropane. Scandinavian Journal of Work Environment and Health 199622 387-391.

5 Bryne J, Mulvihill JJ, Myers MH, Connelly RR, Naughton MD, Steinhorn SC et al. Effects of treatment on fertility in long-term survivors of childhood or adolescent cancer. New England Journal of Medicine 1987317 1315-1321.

6 Whorton MD \& Foliart DE. Mutagenicity, carcinogenicity and reproductive effects of dibromochloropropane (DBCP). Mutation Research 1983123 13-30.

7 Lag M, Søderlund EJ, Omichinski JG, Brunborg G, Holme JA, Dahl JE et al. Effect of bromine and chlorine positioning in the induction of renal and testicular toxicity by halogenated propane. Chemical Research in Toxicology 19914 528-534.

8 Whorton D, Krauss RM, Marshall S \& Milby TH. Infertility in male pesticide workers. Lancet 19772 1259-1261.

9 Spinelli S, Chiodi S, Bacigalupo A, Brasca A, Menada MV, Petti AR et al. Ovarian recovery after total body irradiation and allogeneic bone marrow transplantation: long-term follow up of 79 females. Bone Marrow Transplantation 199414 373-380.

10 Jones GS. Corpus luteum: composition and function. Fertility and Sterility 199054 21-26.

11 Mather JP, Moore A \& Li R-H. Activins, inhibins, and follistatins: further thoughts on a growing family of regulators. Proceedings of the Society for Experimental Biology and Medicine 1997215 209-222.

12 Woodruff TK \& Mather JP. Inhibin, activin and the female reproductive axis. Annual Review of Physiology 199557 219-244.

Received 16 September 1997

Accepted 26 January 1998 